\title{
Visualization of viruses in tumors of rainbow smelt Osmerus mordax
}

\author{
C. M. Morrison ${ }^{1}$, C. T. Leggiadro ${ }^{2}$, D. J. Martell ${ }^{1}$ \\ ${ }^{1}$ Department of Fisheries and Oceans, Biological Sciences Branch, Benthic Fisheries and Aquaculture Division, Box 550 , \\ Halifax, Nova Scotia, Canada B3J 2S7 \\ ${ }^{2}$ Institute for Marine Biosciences, National Research Council of Canada, Halifax, Nova Scotia, Canada B3H $3 Z 1$
}

\begin{abstract}
A virus of typical Herpesvirus morphology was found in papillomas and carcinomas of smelt Osmerus mordax. Icosahedral unenveloped viral nucleocapsids $95 \mathrm{~nm}$ in diameter were found in the enlarged nuclei of infected cells. The nuclei contained dispersed granular chromatin that appeared to be producing viral nucleoids. Most cytoplasmic viral particles were enveloped in electron-dense material, and surrounded by a smooth-membraned vesicle. Some vesicles containing viruses were associated with the enlarged Golgi apparatus, the outer nuclear membrane, or the limiting membrane of the cell.
\end{abstract}

KEY WORDS: Herpesvirus - Papilloma Carcinoma - Smelt - Osmerus mordax · Ultrastructure

\section{INTRODUCTION}

Morrison \& MacDonald (1995) described epidermal tumors which were commonly found in rainbow smelt Osmerus mordax from Nova Scotia (Canada) that varied from small, round preneoplastic lesions with a smooth surface, to larger plaque-like and roughsurfaced papillomas. Some epidermal tumors on the heads of male smelt in freshwater were locally invasive, and there were well-developed squamous cell carcinomas that had invaded the cartilage of the mandible of 2 male smelt, one from brackish and one from seawater. Herman (1988) also described squamous cell carcinomas on the upper jaw of male rainbow smelt from Maine, USA.

The tumors Morrison \& MacDonald (1995) found were similar in gross appearance to those described in European smelt Osmerus eperlanus (Anders \& Möller 1985), but the latter authors found Cowdry type A inclusion bodies, whereas Morrison \& MacDonald (1995), like Herman (1988), did not find these in rainbow smelt. Morrison \& MacDonald (1995) did, however, see finely basophilic intranuclear granules in rainbow smelt tumors that could indicate that viruses were present. Herpesviruses have been observed in ultrastruc- tural studies of the papillomas of European smelt (Anders \& Möller 1985, Wolf 1988) and Atlantic salmon Salmo salar (Shchelkunov et al. 1992), although they were not found in the carcinomas of rainbow smelt from. Maine (Herman 1988). Here we describe ultrastructural studies designed to determine if viruses were present in rainbow smelt tumors found in Nova Scotia.

\section{MATERIALS AND METHODS}

Tumors from male smelt from freshwater were fixed in $1 \%$ glutaraldehyde : $4 \%$ formaldehyde in phosphate buffer (1G4F; McDowell 1978) and prepared for transmission electron microscopy. The first tumor was from an invasive region of a carcinoma on the head of a smelt, $19.5 \mathrm{~cm}$ long, caught in the Meccan River, Cumberland Co., NS; the second was a papilloma with a rough surface on the body, anterior to the dorsal fin, of a smelt $18.3 \mathrm{~cm}$. long; and the third was a plaquelike papilloma with a smooth surface on the operculum of a smelt $17.5 \mathrm{~cm}$ long. Both papillomas were from smelt caught in the Portopique River, Colchester Co., NS. All samples were collected during the spawning run in April. 
Tumors were minced into small cubes $\sim 1 \mathrm{~mm}$ across, dehydrated in acetone and embedded in epon/araldite. Sections $0.5 \mu \mathrm{m}$ in thickness were stained in $1 \%$ toluidine blue with $1 \%$ sodium borate for light microscopy; then ultrathin sections were prepared and stained in $25 \%$ uranyl acetate in methanol and lead citrate (Stempack \& Ward 1964).

Samples of the carcinoma were selectively stained for nucleic acids by staining non-osmicated, ultrathin sections with uranyl acetate and lead citrate as above. Sections were selectively stained for RNA by staining with $5 \%$ uranyl acetate, then removing DNA by floating the grids on $0.2 \mathrm{M}$ EDTA solution for 10 to $60 \mathrm{~min}$ at room temperature and rinsing with distilled water, then staining with lead citrate (Lewis \& Knight 1992).

\section{RESULTS}

Tumor cells had bundles of tonofilaments in the cytoplasm, and were connected by numerous desmosomes typical of spiny layer cells of the epidermis (Fig. 1). However, the cells and their nuclei were enlarged, with many nuclei containing a distinct, round nucleolus, and vacuoles were common between the cells where they were not attached by desmosomes. Mitochondria and a Golgi apparatus with associated vesicles were close to the nucleus, and many vesicles of smooth and rough endoplasmic reticulum and free ribosomes were found throughout the cytoplasm

In all 3 tumors herpesvirus-like particles were found in the nuclei and cytoplasm of some epidermal cells. The nucleus of affected cells had granular chromatin (Fig. 1), and between the clumps of chromatin were unenveloped icosahedral viral capsids, some with nucleoids (Fig. 2). The capsids were $95 \mathrm{~nm}$ in diameter between verticals (average of 35 measurements, $\mathrm{SD}=$ 4.8). The nucleoids ranged in size from 39 to $58 \mathrm{~nm}$ $(\mathrm{n}=10)$, and some were homogenous but others granular in appearance.
Some nuclei contained a paracrystalline body, and in some there was also a small granular chromatin network (Fig. 3) that appeared to contain nucleoids without capsids (Fig. 3, insert).

In the cytoplasm, individual virus particles and aggregates of virus particles were seen. Most viral particles were enveloped in varying amounts of an electron-dense matrix. Some enveloped virions were within smooth-membraned vesicles associated with the Golgi apparatus (Fig. 4), which was enlarged in some cells (Fig. 5), whereas others were in elongate vacuoles near the outer nuclear membrane, in the cytoplasm and near the cell wall (Fig. 6).

The paracrystals consisted of finely granular material, and intranuclear nucleocapsids did not form paracrystalline arrays, although some were found near the paracrystals (Fig. 6 and insert).

Some cytoplasmic viruses were similar to those in the nucleus (Fig. 4), whereas others were enveloped by several electron-dense layers (Fig. 7).

The nucleoids in non-osmicated preparations stained distinctly with uranyl acetate and lead citrate (Fig. 8), but the staining was less intense in EDTA-treated sections (Fig. 9)

\section{DISCUSSION}

Herpesvirus infections can be systemic and are usually latent, becoming active under stressful conditions (Buchanan \& Richards 1982). Many fish herpesviruses are associated with proliferations of the epidermis (Hedrick \& Sano 1989), and in many species the highest prevalences of tumors occur during spawning (Anders 1989), as did the tumors we described in rainbow smelt. Anders (1989) found papillomas only in mature Osmerus eperlanus, and suggested that hormonal changes may result in decreased immune protection, so that systemic host viruses could be activated to induce transformation of normal cells into tumor cells.

Figs. 1 to 5. Herpesvirus-like infection of Osmerus mordax. Fig. 1. Carcinoma. Enlarged epithelial cell with large nucleus containing a prominent, granular heterochromatin network and numerous viral capsids (VC). Enveloped capsids (EC) are present in the cytoplasm, which contains prominent bundles of tonofilaments (T). There is a Golgi apparatus (G) with expanded cisternae and associated vesicles near the nucleus, and several mitochondria (M) are present. The cells are attached by desmosomes (D) with vacuolated regions $(V)$ between. Scale bar $=1 \mu \mathrm{m}$. Fig. 2 . Carcinoma. The capsids are icosahedral, and many have nucleoids $(\mathrm{N})$, which are solid or granular in appearance. Coarse granules are evident in the heterochromatin. Scale bar $=250 \mathrm{~nm}$. Fig. 3. Carcinoma. There is a paracrystal $(\mathrm{P})$, as well as a prominent nucleolus $(\mathrm{Nu})$ and a small region of granular heterochromatin $(H)$ in the nucleus. Scale bar $=1 \mu \mathrm{m}$. Insert: Detail of heterochromatin shown in Fig. 3. Electron-dense units of a similar size to viral nucleoids are present $(N)$. Scale bar $=250 \mathrm{~nm}$. Fig. 4 . Carcinoma. Some nucleocapsids (NC) in the cytoplasm have the same size and shape as those in the nucleus; others are enveloped in electron-dense layers (E), and surrounded by vesicles with a smooth membrane, that are closely associated with cisternae of the Golgi apparatus $(G)$. The outer nuclear membrane is studded with ribosomes $(\mathrm{R})$. Scale bar $=300 \mathrm{~nm}$. Fig. 5. Papilloma with smooth surface. The Golgi body is enlarged, with expanded cisternae. There are numerous vesicles ( $\mathrm{V}$ ) between the Golgı body and the nucleus (N), and enveloped viruses (EV) associated with the Golgi body and the nuclear membrane. Scale bar $=1 \mu \mathrm{m}$ 


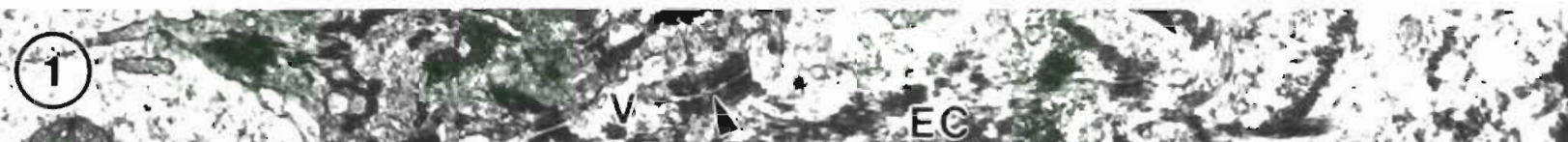

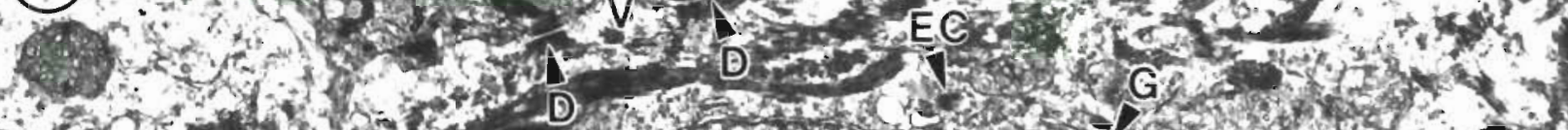

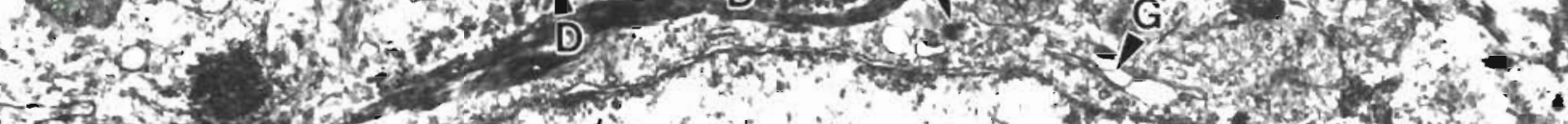

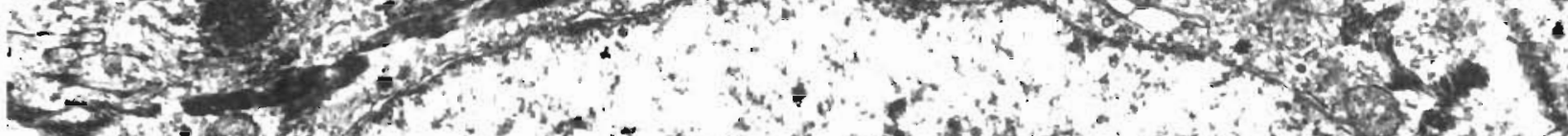

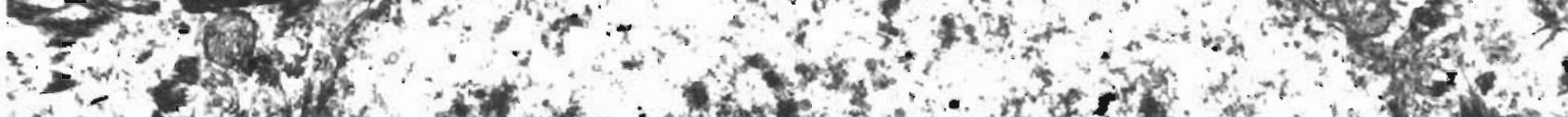

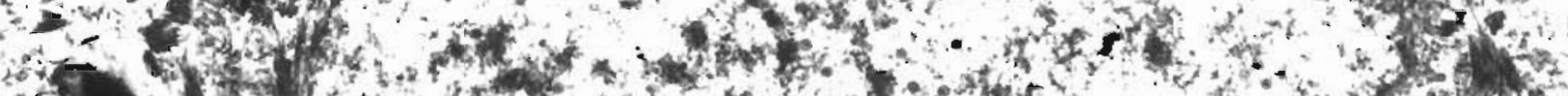

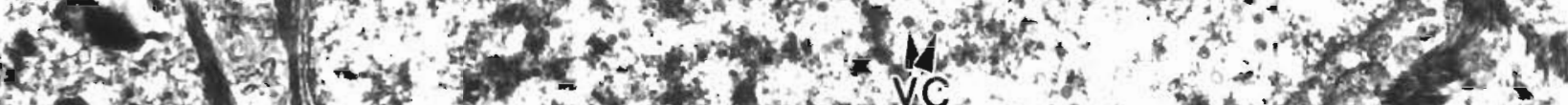

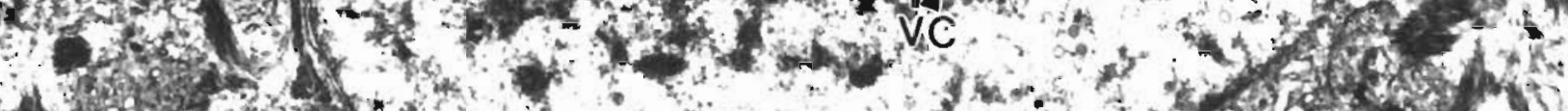

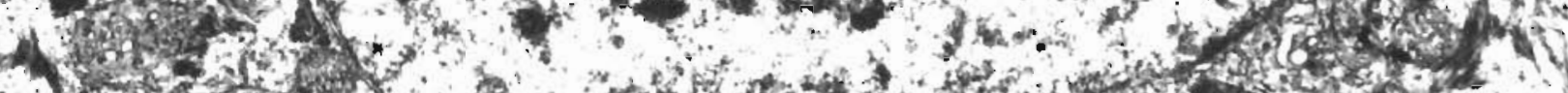

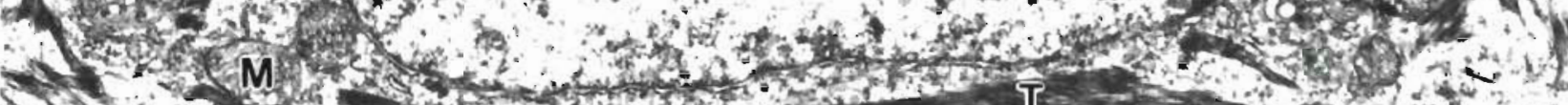

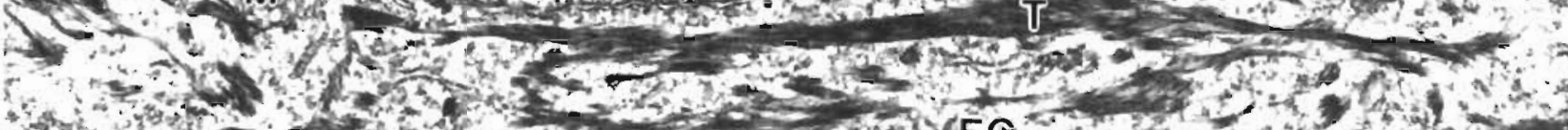

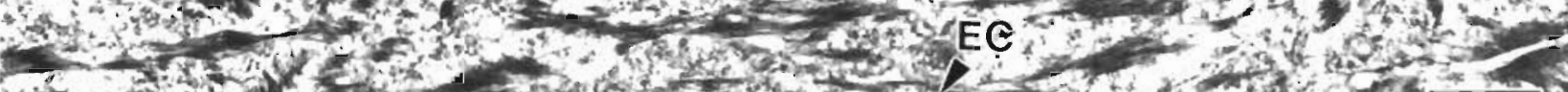

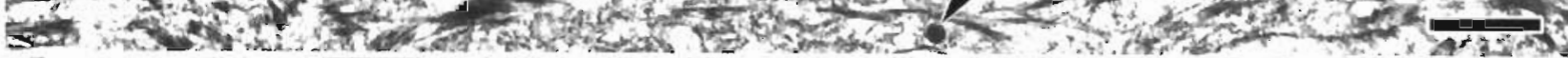

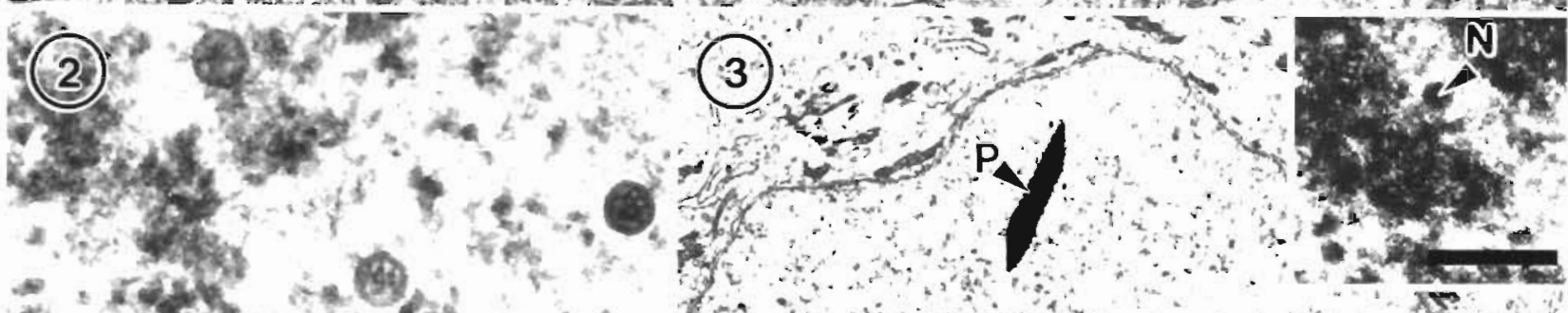

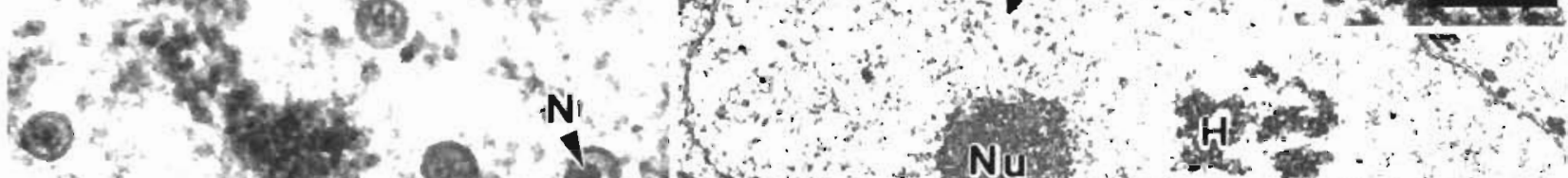

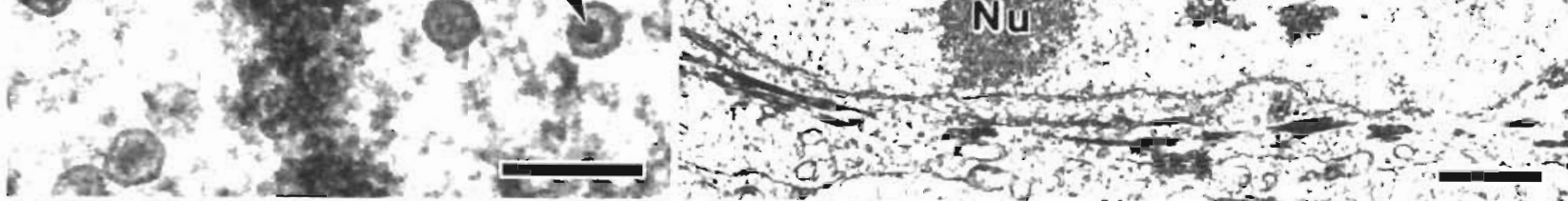

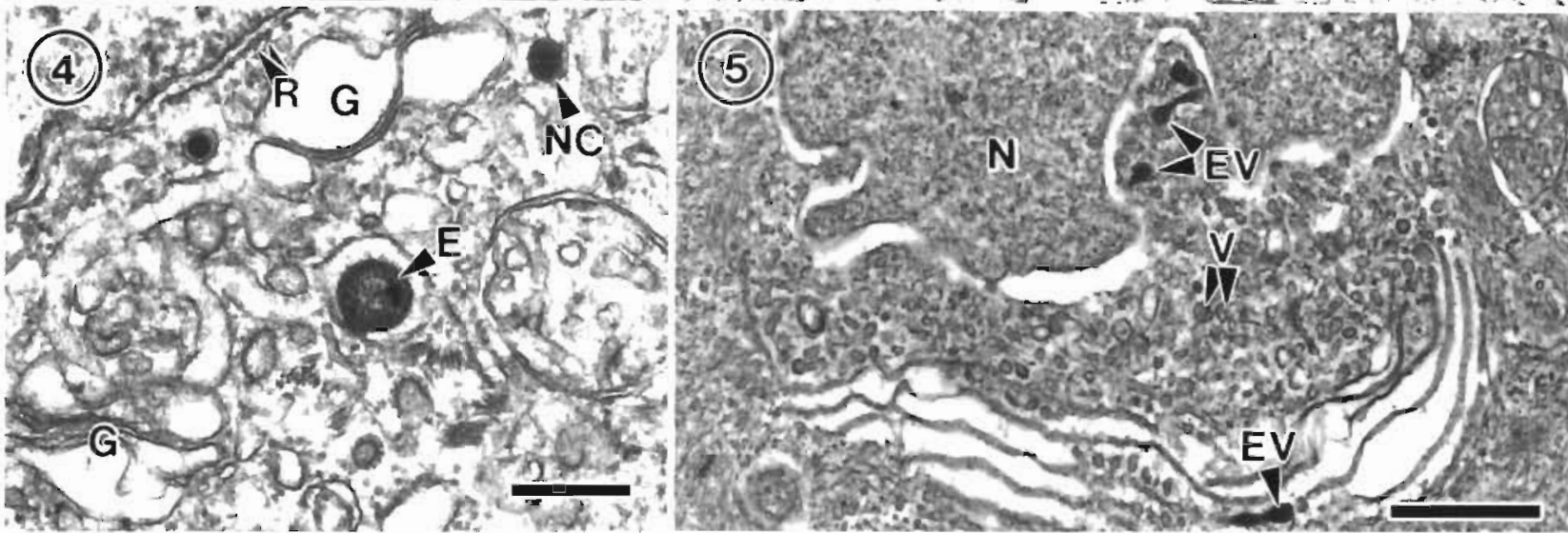




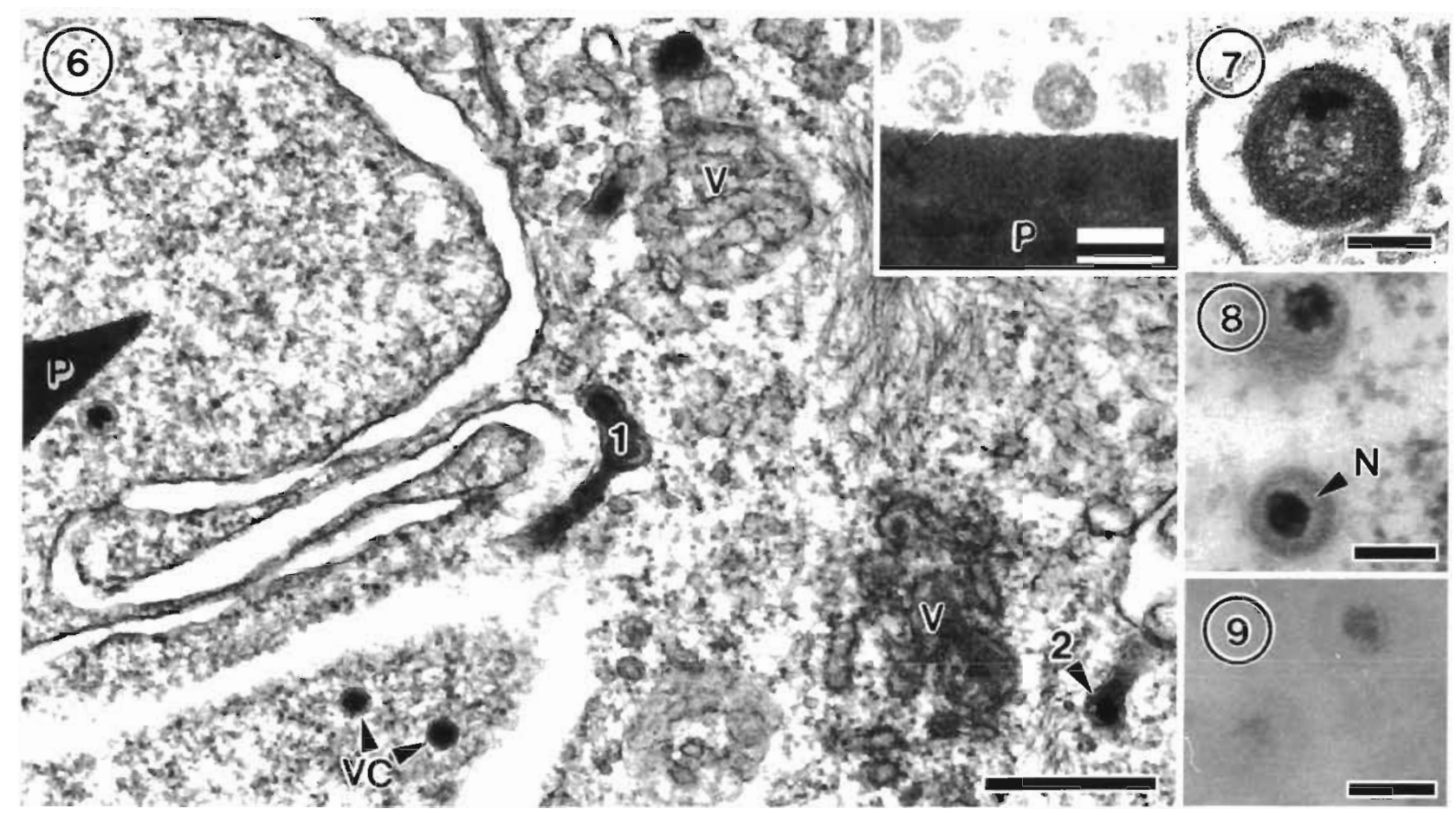

Figs 6 to 9 Herpesvirus-like infection of Osmerus mordax Fig. 6. Paplloma with smooth surface. The nucleus contains several viral capsids (VC), as well as a paracrystal (P). Viruses in the cytoplasm are surrounded by tubular vacuoles. One vacuole (1) is close to the outer nuclear membrane, and another (2) is close to the lumiting membrane of the cell. There are complexes of elongate vacuoles (V) in the cytoplasm. Scale bar $=400 \mathrm{~nm}$. Insert: Detall of paracrystal (P) from same specimen as Fig. 6, showing fine granulanty and closely associated viral capsids Scale bar $=100 \mathrm{~nm}$ Figs. 7 to 9 Carcinoma. Viral particles in the cytoplasm. Fig. 7 Viral capsid surrounded by several electron-dense layers, in a membrane-bound vesicle. Scale bar $=100 \mathrm{~nm}$ Fig. 8 Unosmicated preparation stained with uranyl acetate and lead citrate. The nucleolds (N) of the viruses are clearly stained, but there is little staning of the electron-dense layers. Scale bar $=100 \mathrm{~nm}$. Fig 9. Same specimen as Fig. 8 , incubated for 30 min in EDTA. Much of the staining in the nucleold is removed. Scale bar $=100 \mathrm{~nm}$

Herpesviruses in fish are typically unenveloped in the nucleus and enveloped in the cytoplasm (Buchanan \& Madeley 1978, Anders 1989, Shchelkunov et al. 1992), like those we observed in rainbow smelt tumors. The herpesvirus capsids in the nucleus were similar in size and morphology to those found in European smelt (Anders \& Möller 1985. Wolf 1988, Anders 1989), but the cytoplasmic virions did not have tail-like extensions like some in European smelt. The nucleoids in the rainbow smelt herpesvirus were larger (39 to $58 \mathrm{~nm}$ ) than those of many herpesviruses (25 to $30 \mathrm{~nm}$ ) (Buchanan \& Madeley 1978).

The intranuclear nucleocapsids of many herpesviruses are arranged in paracrystalline arrays (Buchanan \& Madeley 1978), but that was not the case here. Cowdry type A inclusion bodies consist of capsids with and without nucleoids, and are not seen in living cells examined by phase contrast microscopy, or cells fixed with osmium (Pereira 1961) The capsids in our material were dispersed throughout the nucleus, so would appear as fine granules using light microscopy, as described by Morrison \& MacDonald (1995)
Granular chromatin appears to be the source of material for viral nucleoids. Staining of non-osmicated nucleoids with uranyl acetate and lead citrate, and the subsequent diminution of this staining by treatment with EDTA, indicates that DNA is present in viral nucleoids.

In most cases herpesviruses are thought to acquire their envelope layers at the inner nuclear membrane (Buchanan \& Richards 1982), and to be released from the cell through cytoplasmic vacuoles (Buchanan \& Madeley 1978). In our study, many of these vacuoles were apparently produced by an enlarged Golgi body. The osmiophilia of the viral envelope is consistent with lipıd bilayers.

Acknowledgements. Dale Richards and Lorelei Langille, Fishery Officers with the Conservation and Protection Branch of the Department of Fisheries and Oceans, obtamed the smelt samples and fixed them in 1G4F. Anne Moore and Joanne Jellett reviewed the manuscript and provided helpful suggestions. This publication is catalogued as NRCC\#39707 


\section{LITERATURE CITED}

Anders K (1989) A herpes virus associated with an epizootic epidermal papillomatosis in European smelt (Osmerus eperlanus). In: Ahne W, Kurstak E (eds) Viruses of lower vertebrates. Springer-Verlag, Berlin, p 184-197

Anders K, Möller H (1985) Spawning papillomatosis of smelt, Osmerus eperlanus L., from the Elbe estuary. J Fish Dis $8: 233-235$

Buchanan JS, Madeley CR (1978) Studies on Herpesvirus scophthalmi infection of turbot Scophthalmus maximus (L.) ultrastructural observations. J Fish Dis 1:283-295

Buchanan JS, Richards RH (1982) Herpes-type virus diseases of marine organisms. Proc R Soc Edinburgh 81B:151-168

Hedrick RP, Sano T (1989) Herpesviruses of fishes. In: Ahne W, Kurstak E (eds) Viruses of lower vertebrates. SpringerVerlag, Berlin, p 161-170

Herman RL (1988) Squamous cell carcinoma in rainbow smelt Osmerus mordax. Dis Aquat Org 5:71-73

Lewis PR, Knight DP (1992) Cytochemical staining methods

Responsible Subject Editor: F. M. Hetrick, College Park, Maryland, USA for electron microscopy. In: Glauert AM (ed) Practical methods in electron microscopy, Vol 14. Elsevier Science Publishers, Amsterdam, p 92-93

McDowell EM (1978) Fixation and processing. In: Trump BF Jones FT (eds) Diagnostic electron microscopy. John Wiley and Sons, New York, p 113-139

Morrison CM. MacDonald CA (1995) Epidermal tumors on rainbow smelt and Atlantic salmon from Nova Scotia, Canada. J Aquat Anim Health 7:241-250

Pereira HG (1961) The cytopathic effect of animal viruses. Adv Virus Res 8:245-285

Shchelkunov IS, Karaseva TA, Kadoshnikov YUP (1992) Atlantic salmon papillomatosis: visualization of herpesvirus-like particles in skin growths of affected fish. Bull Eur Ass Fish Pathol 12:28-31

Stempack JG, Ward RT (1964) An improved staining method for electron microscopy. J Cell Biol 22:697-701

Wolf K (1988) Smelt papilloma herpesvirus. In: Wolf K (ed) Fish viruses and fish viral diseases. Cornell University Press, New York, p 375-377

Manuscript first received: July 31, 1995

Revised version accepted: January 9, 1996 